\title{
The correlation between IL-33 and inflammation factors in rheumatoid arthritis patients in vivo and in fibroblast-like synoviocytes in vitro
}

Jing Wu

Zhujiang Hospital https://orcid.org/0000-0002-6173-3254

Qiang Li

Zhujiang Hospital

Jia-Xin Deng

Zhujiang Hospital

Jin-Jun Zhao ( $\nabla$ zhao7749@126.com )

Southern Medical University Nanfang Hospital

Qing-Hong Yu ( $\sim$ yuqinghong@smu.edu.cn)

Zhujiang Hospital

Research article

Keywords: Interleukin-33, rheumatoid arthritis, fibroblast-like synoviocytes, cytokines, chemokines

Posted Date: March 9th, 2020

DOI: https://doi.org/10.21203/rs.3.rs-16415/v1

License: (a) This work is licensed under a Creative Commons Attribution 4.0 International License. Read Full License 


\section{Abstract}

Background: Interleukin-33 (IL-33) is a member of the IL-1 family of cytokines whose role remains controversial in rheumatoid arthritis (RA), because no clear conclusion has been established regarding the relationship between IL-33 and other cytokines and chemokines. The present study was conducted to evaluate the correlation of IL-33 with other cytokines and chemokines in serum and the synovia, and to explore the nature of the relationship.

Results: IL-33 was found to exhibit an inverted-U-shaped correlation with multiple cytokines and chemokines in synovial fluid, including IL-6, IL-1ß, CXCL8 (IL-8), CXCL9 (MIG) and CXCL10 (IP-10), but not in serum. Moreover, in vitro experiments confirmed that IL-33 also exhibits Utype dose-dependent regulation of FLS function.

Conclusions: IL-33 exhibit an inverted-U-shaped correlation with multiple cytokines and chemokines in synovial fluid of RA patients. IL-33 affects the secretion of cytokines and chemokines in the synovium in a U-type dose-dependent relationship.

\section{Background}

Rheumatoid arthritis (RA) is a chronic and refractory autoimmune joint disease, characterized by the proliferation of synoviocytes in inflamed synovia and the expression of inflammatory cytokines and chemokines in synoviocytes [1]. Multiple pro-inflammatory and inflammatory cytokines have been thought to participate in the development of RA. A variety of cytokines and chemokines are present in the synovium of RA patients which play an important role in the maintenance of the inflammatory response [2, 3]. Important proinflammation cytokines, such as IL-33, IL-1 $\beta$, IL-6, IL-8 and TNF-a, and chemokines such as CXCL9 and CXCL10 are considered markers for the diagnosis of RA and represent therapeutic targets [3-9]. A complex mechanistic network exists between these cytokines and chemokines.

IL-33 is a member of the IL-1 family of cytokines [10]. Supporting evidence regarding the relationship between IL-33 and pathogenesis of RA has been provided by Matsuyama and colleagues, in which IL-33 levels have been found to be elevated in the serum and synovial fluid of RA-patients, demonstrating a positive correlation with disease activity[11]. IL-33 is expressed in human RA synovial fluid and released from FLS following stimulation with TNF- $a$ and IL-1 $\beta[11,12]$. IL-33 can activate human mast cells to release CXCL8 in RA patients[13]. One study has indicated that IL-33 is able to enhance the expression of CXCL9 and CXCL10 in wild-type mice with colitis [14]. IL-33 has an important role and a complicated relationship with cytokines and chemokines in RA [12, 15, 16]. However, the role of IL-33 remains controversial, a number of studies suggesting that it promotes inflammation[17], while others show that the response is inhibitory [18]. A confounding observation is that high levels of IL-33 can be detected in the serum or synovia fluid of just one third to one half RA patients, suggesting that IL-33 is widely variable in RA patients $[11,19,20]$. A significant number of patients with RA have low levels of IL-33 in serum but still exhibit high disease activity [19]. Since contrary results are increasingly observed in RA, we hypothesize that the concentrations of IL-33 and other cytokines and chemokines might not be linearly correlated, but a more complex polynomial correlation should be further investigated. The present research study aimed to establish a correlation curve model of cytokines (CXCL8, CXCL9, and CXCL10) and chemokines (IL-1 $\beta$, TNF- $a$, and IL-6) with IL-33 in serum and synovia, and to explore the nature of the relationship.

\section{Results}

\section{Baseline clinical and demographics features}

A total of 96 consecutive patients with RA were recruited, from which 40 serum samples ( 35 women and 5 men, mean age $51.80 \pm 13.37$ years) and 56 synovial samples (43 women and 13 men, mean age $48.85 \pm 13.39$ years) were obtained. Patients characteristics are displayed in Table 1, below.

\section{Cytokines and chemokines levels in patients with RA}

At baseline, there were no differences in IL-33, MIG and IL- 6 concentrations between the synovial and serum samples of RA patients (Figure $1 \mathrm{~A}, \mathrm{~B}$ and D). IP-10 concentration was significantly higher in synovial fluid than in serum (Figure $1 \mathrm{C}$ ). IL-8, TNF- $\alpha$ and IL- $\beta$ concentrations were significantly higher in serum than in synovial fluid (Figure $1 \mathrm{E}, \mathrm{F}$ and $\mathrm{G}$ ).

\section{IL-33 concentration follows an inverted-U-shaped curve in response to cytokines and chemokines}

IL-33 concentration exhibited an inverted-U-shaped curve in response to IL-6, IL-13, CXCL8 (IL-8), CXCL9 (MIG) and CXCL10 (IP-10) but not TNF-a in synovial fluid of RA patients (Figure 2). The same IL-33 inverted-U-shaped correlation was observed after treatment with CXCL9 
(MIG) but not CXCL10 (IP-10), TNF-a, IL-6, IL-1 $\beta$ or CXCL8 (IL-8) in the serum of RA patients (Figure 3).

\section{mRNA and protein expression levels of IL-6, CXCL 8, CXCL9, CXCL10, IL-1 $\beta$ and TNF- $\alpha$ in FLS stimulated by IL-33}

IL-33 affected the mRNA expression of IL-6, CXCL8, CXCL9, CXCL10, IL-1 $\beta$ and TNF- $\alpha$ in FLS. However, only protein expression of IL-6, IL-8, CXCL10 and TNF- $a$ was detectable in the supernatants of the FLS cell culture. CXCL9 and IL-1 $\beta$ protein expression was not detected in the supernatants of FLSs, even at a low level. IL-33 affected both mRNA and proteins expression of IL-6 in FLS. A high response of FLS at a concentration of $50 \mathrm{ng} / \mathrm{ml} \mathrm{IL-33} \mathrm{suggests} \mathrm{that} \mathrm{it} \mathrm{has} \mathrm{a} \mathrm{narrow} \mathrm{working} \mathrm{concentration} \mathrm{on} \mathrm{FLSs} \mathrm{(Figure} 4 \mathrm{~A}$ ). A greater response at $4 \mathrm{~h}$ than $24 \mathrm{~h}$ suggests that IL-33 is effective over a precise time frame in FLSs. Over time, the effect cof IL-33 on IL-6 secretion by FLS changed (Figure 4 B). Different to IL-6, the expression of IL-8 reached a peak after $24 \mathrm{~h}$ at a concentration of $50 \mathrm{ng} / \mathrm{ml}$ of IL-33 (Figures 4 C, D). CXCL9 mRNA expression was up-regulated in $50 \mathrm{ng}$ and $100 \mathrm{ng}$ after $4 \mathrm{~h}$, but only $50 \mathrm{ng}$ after $24 \mathrm{~h}$, while CXCL9 protein could not be detected in the FLS culture supernatant (Figure 4 E). IL-6, IL-8, and IL-1 $\beta$ mRNA were detected at high levels in both 50ng and 100ng concentrations of IL-33 at both time points, but protein expression (Figure $4 \mathrm{~F}$ ). CXCL10 mRNA expression was down-regulated as the concentration of IL-33 increased. The ELISA results also demonstrated that CXCL10 protein expression decreased as the concentration of IL-33 increased after 24h. Conversely, TNF-a and IL-17 increased CXCL10 mRNA expression in FLS (Figure $4 \mathrm{H}$ ). TNF-a was not affected by different concentrations of IL-33, or by IL-17 (Figures $4 \mathrm{I}, \mathrm{J}$ ).

\section{Discussion}

Previous studies have shown that IL-33 is expressed in human RA synovium, promoting articular inflammation [12, 15, 20], but the underlying mechanisms have not been fully elucidated and opposite experimental results have been observed on numerous occasions. In vivo, injection of IL-33 has been shown to exacerbate joint inflammation in a K/BxN serum-transfer mouse model of arthritis [17]. However, a separate study provided conflicting results, indicating that injection of IL-33 ameliorated joint inflammation in the same mouse model [18]. Interestingly, another two research groups observed similar contradictory results: Jérôme Biton found that IL-33 was able to suppress inflammation in CIA mice [21], but Xu demonstrated that IL-33 was a critical proinflammatory cytokine causing fibroblast activation in CIA mice[12]. We carefully analyzed two papers with contradictory findings and found that the different results may have been caused due to the different dosage of IL-33 in injected. Therefore, we realized that whether the effect of IL-33 was proinflammatory or inhibitory maybe related to its concentration.

To confirm this hypothesis, we conducted an additional series of experiments. Firstly, the concentrations of a variety of cytokines and chemokines were measured in synovia and serum. Of note, the level of IP-10 was considerably higher in synovial fluid than in serum, indicating that inflamed joints constitute the primary source of circulating IP-10 in arthritis. Conversely, IL-8, TNF- $\alpha$ and IL-1 $\beta$ levels were substantially higher in serum than in synovial fluid. Secondly, we investigated the association of IL-33 with other cytokines and chemokines in RA patients. As expected, IL-33 was not linearly correlated with other cytokines and chemokines but exhibited an inverted-U-shaped relationship. In the present study, we found that IL-33 exhibited an inverted-U-shaped correlation with IL-6, IL-8, IL-1 $\beta$, CXCL9 and CXCL10 but not TNF-a in the synovia of RA patients, although other studies have demonstrated that TNF-a was able to stimulate IL-33 release in mouse experiments and in cell culture. [22]. Our research suggests that IL-33 has a more specific role in synovia than in serum, since this Ushaped relationship occurs only in synovia. Synovia is principally produced by synovial cells, and so we aimed to explore the role of IL-33 in synovial cells. The experiment was designed with IL-33 concentrations that stimulated FLSs. As expected, the most exciting result was that specific concentrations of IL-33 were important in FLS cultures, $10 \mathrm{ng} / \mathrm{ml}$ being too low to cause an impact on FLS, but $150 \mathrm{ng} / \mathrm{ml} \mathrm{IL-33} \mathrm{too}$ high. This response was consistent with the U-type correlation between IL-33 and other cytokines observed in synovial fluid. The most appropriate concentration of IL-33 was $50 \mathrm{ng} / \mathrm{ml}$ for $20000 \mathrm{FLSs}$, although its influence was not comparable with IL-17 and TNF-a, which strongly influenced FLSs. We considered other studies that demonstrated the negative results[23] might be because IL-33 operated within a narrow range of working concentrations, and the most appropriate ratio of IL-33 concentration/cell number was important in FLS cultures. Time points were an additional factor that could affect FLS, culturing for $4 \mathrm{~h}$ being more effective than for $24 \mathrm{~h}$ regarding IL-6 release, suggesting that IL-33 affect FLS over a precise time frame. IL-6 was released earlier than IL-8, suggesting that different cytokines released by FLSs were controlled by different mechanisms. We found a significant inverted-U-shaped influence on IL- 6 and IL-8 but not CXCL10 and TNF-a, so the results imply that different cytokines released by FLSs were controlled by different mechanisms. IL-33 regulated the production of IL-1 $\beta$ in FLS in an inverted-U-shaped manner, and combined with other research findings established that IL-1 $\beta$ regulated the production of IL-33 in FLS [22], demonstrating that IL-33 plays a key role in the positive and negative feedback mechanisms with IL-1 $\beta$. In this study, we were concerned about the relationship between IL-33 and other cytokines and chemokines. We initially discovered the inverted-U-shaped relationship between IL-33 and the chemokines CXCL8, CXCL9 and CXCL10 in synovia. These results very important in RA, suggesting that IL-33 has the potential capability to recruit and regulate inflammatory cells. 


\section{Conclusions}

In the present study, we reported that IL-33, a recently-described member of the IL-1 family of cytokines, exhibits an inverted-U-shaped correlation with multiple cytokines and chemokines in synovial fluid, including IL-6, IL-1 $\beta$, CXCL8 (IL-8), CXCL9 (MIG) and CXCL10 (IP-10) but not in serum. IL-33 also triggered the expression of the pro-inflammatory cytokines IL- 6 and IL-1 $\beta$, and chemokines CXCL8 and CXCL9 in a U-shaped dose-dependent manner in RA-FLS.

\section{Methods}

\section{Patient enrollment}

A total of 96 Patients with RA who had presented at the rheumatology clinic of ZhuJiang Hospital of Southern Medical University were recruited to the study. All patients fulfilled the 2010 rheumatoid arthritis classification criteria [24].Samples of serums and synovial fluid, as appropriate were collected from RA patients after obtaining signed informed consent.

\section{Human FLS culture}

Synovial tissue samples were obtained by knee joint arthroscopy from the knees of five active RA patients, DAS28>5.1. All RA patients fulfilled the 2010 rheumatoid arthritis classification criteria. Synovial tissues were diced into 1-2 $\mathrm{mm}^{3}$ pieces, cultured with Dulbecco's modified eagle medium (DMEM) containing $10 \%$ fetal bovine serum, $100 \mathrm{U} / \mathrm{ml}$ penicillin and $100 \mathrm{ug} / \mathrm{ml}$ streptomycin, then incubated in a humidified atmosphere containing 5\% CO2. The culture medium was refreshed every 3-4 days. Cells at passage 3 to 6 were used for experiments.

\section{Synovial cell activation}

RA-FLSs were seeded in the wells of 24-well plates at a density of $2 \times 10^{4}$ cells/well for $24 \mathrm{~h}$, thenc10ng, $50 \mathrm{ng}, 100 \mathrm{ng}$ or $150 \mathrm{ng} / \mathrm{ml}$ human IL-

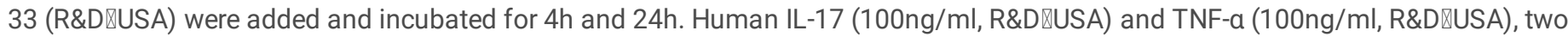
cytokines known to activate synoviocytes were performed as positive controls.

\section{Quantitative PCR}

Total RNA was isolated from RA-FLSs using Trizol reagent (Invitrogen, USA) in accordance with the manufacturer's protocols. Reverse transcription was conducted using first-strand cDNA synthesis (TaKaRa, China). Real-time PCR was performed using a SYBR Premix ExTaq kit (TaKaRa, China) to assess the expression of IL-6, CXCL8, CXCL9, CXCL10, IL-1 $\beta$ and TNF-a.

\section{ELISA assays}

Concentrations of cytokines and chemokines in serum and synovial fluid samples were measured using ELISA assays, including IL-33 (R\&D, USA), IL-1 $\beta$ (R\&D囚USA), TNF-a (Thermo Fisher Scientific, USA), IL-6 (Thermo Fisher Scientific, USA), IL-8 (Thermo Fisher Scientific, USA) $₫ \mathrm{MIG}$ (Invitrogen, USA) and IP-10 (Invitrogen, USA). After stimulation of $2 \times 10^{4}$ RA-FLSs with human IL-33 as described above, the supernatants of the FLS cell cultures were collected and IL-6, IL-8, MIG, IP-10, TNF- $\alpha$ and IL-1 $\beta$ concentrations were quantified. The optical density (OD) values of each sample were measured at $450 \mathrm{~nm}$.

\section{Statistical analysis}

Statistical analyses were performed using IBM SPSS 24.0 and GraphPad Prism 5.0. Data are presented as means \pm standard deviation (SD) or medians (QR). Differences between groups were analyzed using Kruskal-Wallis test (more than two groups), or a Mann-Whitney U test (two groups). A second-order polynomial regression analyses were performed using SPSS 24.0 to quantify the associations among the variables. Other statistical tests were conducted by ANOVA. All statistical tests and confidence intervals were two-sided, with $P<0.05$ considered statistically significant.

\section{Declarations}

\section{Ethics approval and consent to participate}

The study is approved by Ethics Committee of ZhuJiang Hospital of Southern Medical University. This is to certificate that the research design and methods are in accordance with the requirements of the ethical standards in the 2013 Declaration of Helsinki regulations and procedures regarding to human subject protection in laws. And written informed consent was obtained from all study participants. 
Not applicable.

\section{Competing interests}

The authors declare that the research was conducted in the absence of any commercial or financial relationships that could be construed as a potential conflict of interest.

\section{Funding}

This study was supported by the National Natural Science Foundation of China (grant no. 81601397) and National Natural Science Foundation of China (grant no. 81771727).

\section{Availability of data and materials}

The datasets used and analyzed during the present study are available from the corresponding author on reasonable request.

Authors' contributions

JW, QL, JX D and J S performed experiments. JW and QL conceived the study and analyzed the results. JJZ and QH Y supervised the study and prepared the manuscript. All authors read and approved the final manuscript.

Acknowledgements

None.

\section{References}

1. Nanki T, Nagasaka K, Hayashida K, Saita Y, Miyasaka N: Chemokines regulate IL-6 and IL-8 production by fibroblast-like synoviocytes from patients with rheumatoid arthritis. J Immunol 2001, 167(9):5381-5385.

2. Szekanecz Z, Kim J, Koch AE: Chemokines and chemokine receptors in rheumatoid arthritis. Seminars in immunology 2003, 15(1):1521.

3. Kuan WP, Tam LS, Wong CK, Ko FW, Li T, Zhu T, Li EK: CXCL 9 and CXCL 10 as Sensitive markers of disease activity in patients with rheumatoid arthritis. The Journal of rheumatology 2010, 37(2):257-264.

4. Ruschpler P, Lorenz P, Eichler W, Koczan D, Hanel C, Scholz R, Melzer C, Thiesen HJ, Stiehl P: High CXCR3 expression in synovial mast cells associated with CXCL9 and CXCL10 expression in inflammatory synovial tissues of patients with rheumatoid arthritis. Arthritis research \& therapy 2003, 5(5):R241-252.

5. Pandya JM, Lundell AC, Andersson K, Nordstrom I, Theander E, Rudin A: Blood chemokine profile in untreated early rheumatoid arthritis: CXCL10 as a disease activity marker. Arthritis research \& therapy 2017, 19(1):20.

6. Siebert S, Tsoukas A, Robertson J, McInnes I: Cytokines as therapeutic targets in rheumatoid arthritis and other inflammatory diseases. Pharmacological reviews 2015, 67(2):280-309.

7. Brennan FM, Mclnnes IB: Evidence that cytokines play a role in rheumatoid arthritis. The Journal of clinical investigation 2008, 118(11):3537-3545.

8. Hueber AJ, Asquith DL, Mclnnes IB, Miller AM: Embracing novel cytokines in RA - complexity grows as does opportunity! Best practice \& research Clinical rheumatology 2010, 24(4):479-487.

9. Mateen S, Zafar A, Moin S, Khan AQ, Zubair S: Understanding the role of cytokines in the pathogenesis of theumatoid arthritis. Clinica chimica acta; international journal of clinical chemistry 2016, 455:161-171.

10. He R, Yin H, Yuan B, Liu T, Luo L, Huang P, Dai L, Zeng K: IL-33 improves wound healing through enhanced M2 macrophage polarization in diabetic mice. Mol Immunol 2017, 90:42-49.

11. Matsuyama Y, Okazaki H, Tamemoto H, Kimura H, Kamata Y, Nagatani K, Nagashima T, Hayakawa M, Iwamoto M, Yoshio T et al: Increased levels of interleukin 33 in sera and synovial fluid from patients with active rheumatoid arthritis. The Journal of rheumatology 2010, 37(1):18-25.

12. Xu D, Jiang HR, Kewin P, Li Y, Mu R, Fraser AR, Pitman N, Kurowska-Stolarska M, McKenzie AN, Mclnnes IB et al: IL-33 exacerbates antigen-induced arthritis by activating mast cells. Proceedings of the National Academy of Sciences of the United States of America 
2008, 105(31):10913-10918.

13. Rivellese F, Suurmond J, Habets K, Dorjee AL, Ramamoorthi N, Townsend MJ, de Paulis A, Marone G, Huizinga TW, Pitzalis C et al: Ability of Interleukin-33- and Immune Complex-Triggered Activation of Human Mast Cells to Down-Regulate Monocyte-Mediated Immune Responses. Arthritis \& rheumatology 2015, 67(9):2343-2353.

14. Pushparaj PN, Li D, Komai-Koma M, Guabiraba R, Alexander J, McSharry C, Xu D: Interleukin-33 exacerbates acute colitis via interleukin-4 in mice. Immunology 2013, 140(1):70-77.

15. Palmer G, Talabot-Ayer D, Lamacchia C, Toy D, Seemayer CA, Viatte S, Finckh A, Smith DE, Gabay C: Inhibition of interleukin-33 signaling attenuates the severity of experimental arthritis. Arthritis and rheumatism 2009, 60(3):738-749.

16. Yuan FL, Li X, Lu WG, Li CW, Xu RS, Dong J: IL-33: a promising therapeutic target for rheumatoid arthritis? Expert opinion on therapeutic targets 2011, 15(5):529-534.

17. Xu D, Jiang HR, Li Y, Pushparaj PN, Kurowska-Stolarska M, Leung BP, Mu R, Tay HK, McKenzie AN, Mclnnes IB et al: IL-33 exacerbates autoantibody-induced arthritis. J Immunol 2010, 184(5):2620-2626.

18. Anthony RM, Kobayashi T, Wermeling F, Ravetch JV: Intravenous gammaglobulin suppresses inflammation through a novel T(H)2 pathway. Nature 2011, 475(7354):110-113.

19. Mu R, Huang HQ, Li YH, Li C, Ye H, Li ZG: Elevated serum interleukin 33 is associated with autoantibody production in patients with rheumatoid arthritis. J Rheumato/ 2010, 37(10):2006-2013.

20. Talabot-Ayer D, McKee T, Gindre P, Bas S, Baeten DL, Gabay C, Palmer G: Distinct serum and synovial fluid interleukin (IL)-33 levels in rheumatoid arthritis, psoriatic arthritis and osteoarthritis. Joint Bone Spine 2012, 79(1):32-37.

21. Biton J, Khaleghparast Athari S, Thiolat A, Santinon F, Lemeiter D, Herve R, Delavallee L, Levescot A, Roga S, Decker P et al: In Vivo Expansion of Activated Foxp3+ Regulatory T Cells and Establishment of a Type 2 Immune Response upon IL-33 Treatment Protect against Experimental Arthritis. J Immuno/ 2016, 197(5):1708-1719.

22. Lee EJ, So MW, Hong S, Kim YG, Yoo B, Lee CK: Interleukin-33 acts as a transcriptional repressor and extracellular cytokine in fibroblastlike synoviocytes in patients with rheumatoid arthritis. Cytokine 2016, 77:35-43.

23. Machado CRL, G.G.Resende, R.B.V.Macedo, V.C.Nascimento, T.P.Sliva, Kakehasi AM, M.V.M.Andrade: Fibroblast-like synoviocytes may not be the target of il-33 in the joint phisiopathology. Annals of the rheumatic diseases 2017, 76(Suppl 2):1056.

24. Aletaha D, Neogi T, Silman AJ, Funovits J, Felson DT, Bingham CO, 3rd, Birnbaum NS, Burmester GR, Bykerk VP, Cohen MD et al: 2010 Rheumatoid arthritis classification criteria: an American College of Rheumatology/European League Against Rheumatism collaborative initiative. Arthritis and rheumatism 2010, 62(9):2569-2581.

\section{Tables}

Table1. RA Patients characteristics

\begin{tabular}{|c|c|c|c|c|c|c|c|c|c|}
\hline $\mathrm{n}$ & $\begin{array}{c}\text { Gender } \\
(\mathrm{M} / \mathrm{F})\end{array}$ & Age (y) & $\begin{array}{c}\begin{array}{c}\text { IL-33 } \\
(\mathrm{pg} / \mathrm{ml})\end{array} \\
\end{array}$ & $\begin{array}{c}\text { MIG } \\
(\mathrm{pg} / \mathrm{ml})\end{array}$ & $\begin{array}{c}\begin{array}{c}\mathrm{IP}-10 \\
(\mathrm{pg} / \mathrm{ml})\end{array} \\
\end{array}$ & $\begin{array}{c}\begin{array}{c}\mathrm{IL}-6 \\
(\mathrm{pg} / \mathrm{ml})\end{array} \\
\end{array}$ & $\begin{array}{c}\begin{array}{c}\mathrm{IL}-8 \\
(\mathrm{pg} / \mathrm{ml})\end{array} \\
\end{array}$ & $\begin{array}{r}\text { TNF- } \alpha \\
(\mathrm{pg} / \mathrm{ml}) \\
\end{array}$ & $\begin{array}{c}\begin{array}{c}\mathrm{IL}-1 \beta \\
(\mathrm{pg} / \mathrm{ml})\end{array} \\
\end{array}$ \\
\hline \multirow[t]{2}{*}{40} & $5 / 35$ & $51.80 \pm 13.37$ & $36.46(16.05,191.92)$ & 1081.88(460.67, & $143.40(90.50$ & $94.95(3.33,172.46)$ & 675.23(117.55, & $20.17(12.02$ & $12.85(10.21$ \\
\hline & & & & 1384.15) & $316.40)$ & & 1042.17) & $32.53)$ & 22.73) \\
\hline \multirow[t]{2}{*}{56} & $13 / 43$ & $48.85 \pm 13.39$ & $40.45(22.40,80.36)$ & $563.59(404.68,1176.68)$ & 201.12 & $34.13(9.53,222.03)$ & $14.13(6.74,44.44)$ & $9.68(3.38,16.22)$ & 8.56(1.74, \\
\hline & & & & & $(269.35,606.46)$ & & & & 9.45) \\
\hline
\end{tabular}

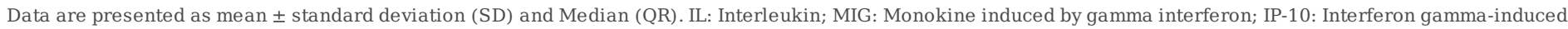
protein 10 .

\section{Figures}



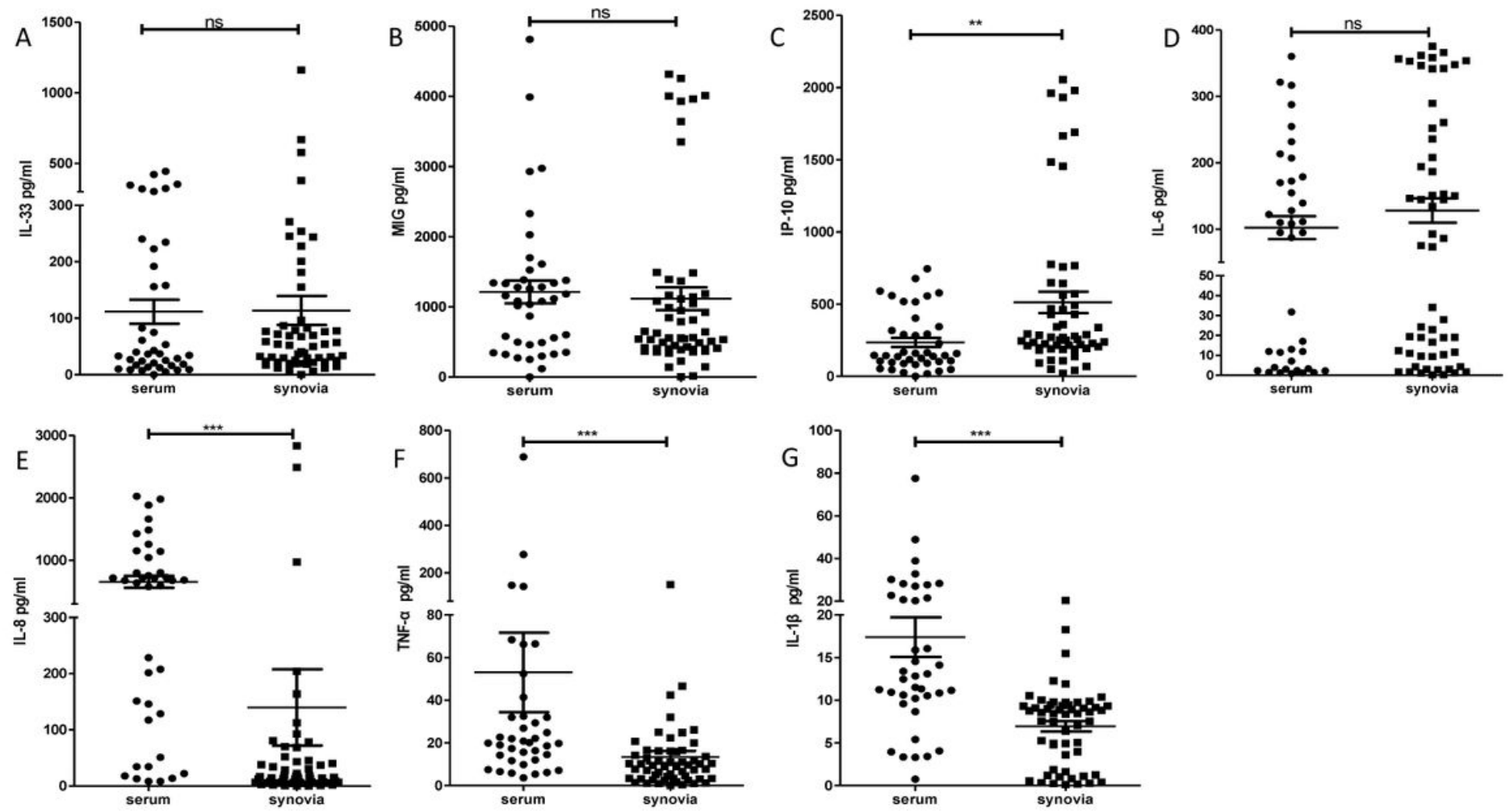

Figure 1

Serum and synovia cytokines and chemokines concentration, measured by ELISA, were obtained from 96 patients with RA, 40 serum, 56 synovia. A. IL-33 was detected in RA synovia compared with serum $(\mathrm{p}=0.640)$; $\mathrm{B}$ : MIG was detected in RA synovia compared with serum $(p=0.183)$. C: IP-10 was detected in RA synovia compared with serum $(p=0.001)$. D: IL-6 was detected in RA synovia compared with serum $(p=0.376)$. E: IL-8 was detected in RA synovia compared with serum $(p=0.000)$. F: TNF-a was detected in RA synovia compared with serum $(p=0.000)$. G: IL-1 $\beta$ was detected in RA synovia compared with serum $(p=0.000) * * P<0.01,{ }^{\star *} * P<0.001$ as assessed by Mann-Whitney $U$ test, as appropriate. 

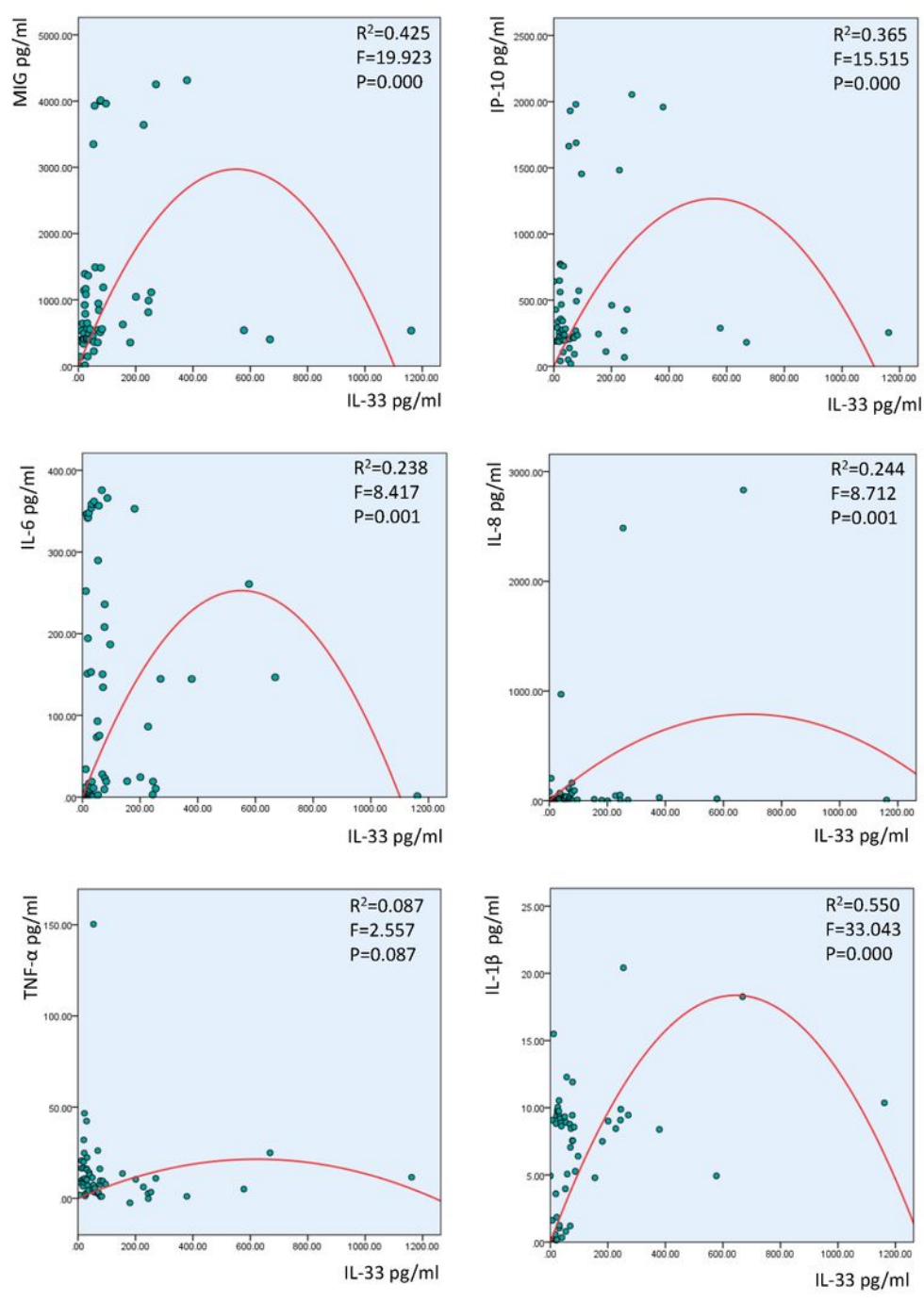

- Synovia samples

Quadratic regression curve

\section{Figure 2}

The Inverted-U-shaped correlations showed between synovia IL-33 and CXCL9 (MIG), CXCL10 (IP-10), IL-6, CXCL8 (IL-8), TNF- $a$ and IL-1ß. Second-order poly-nomial regression curve were made by SPSS 24.0. $\mathrm{P}<0.05$ as assessed by ANOVA test. 

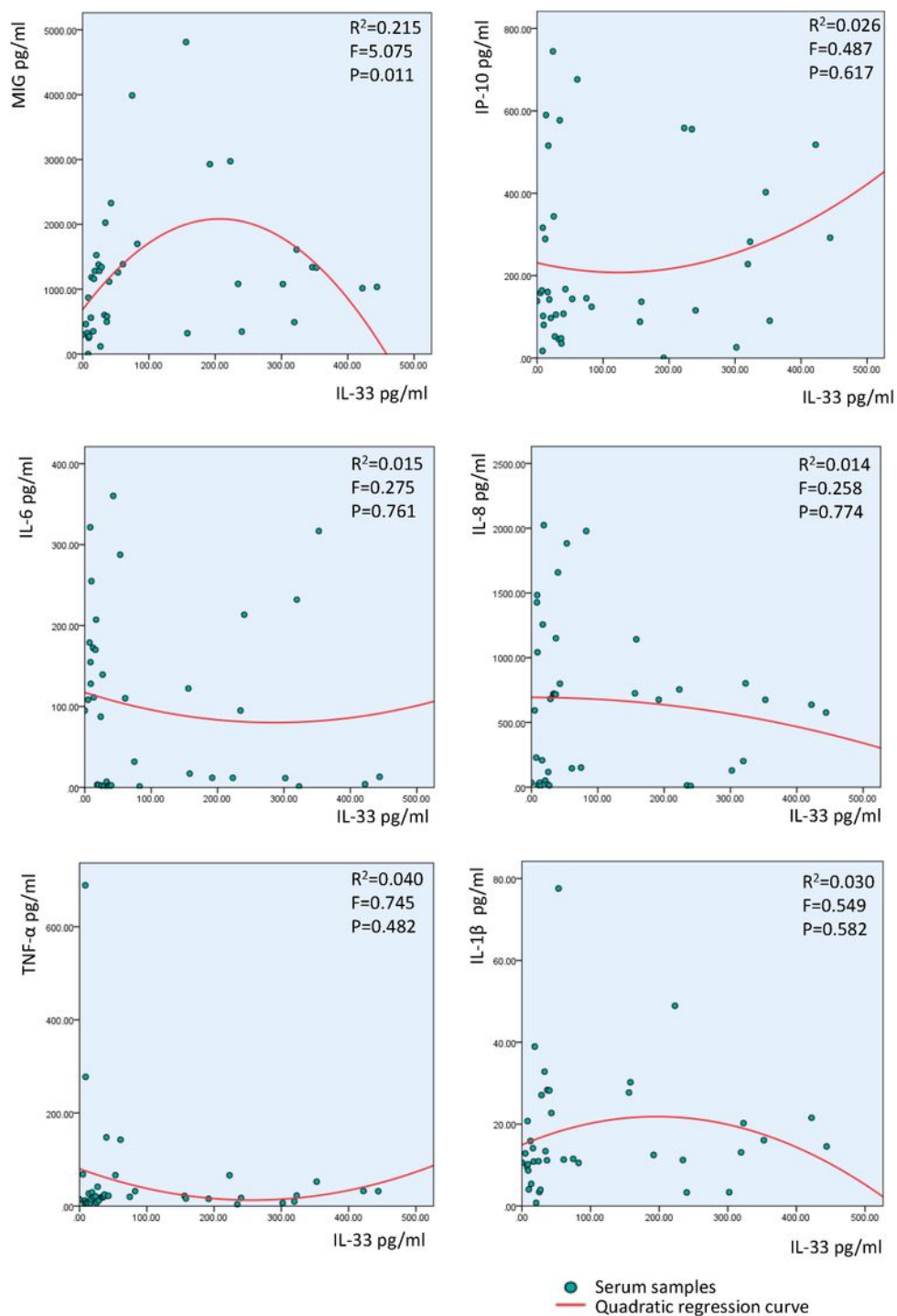

\section{Figure 3}

The Inverted-U-shaped correlations showed between serum IL-33 and CXCL9 (MIG), CXCL10 (IP-10), IL-6, CXCL8 (IL-8), TNF-a and IL-1ß. Second-order polynomial regression curve were made by SPSS $24.0 . P<0.05$ as assessed by ANOVA test. 

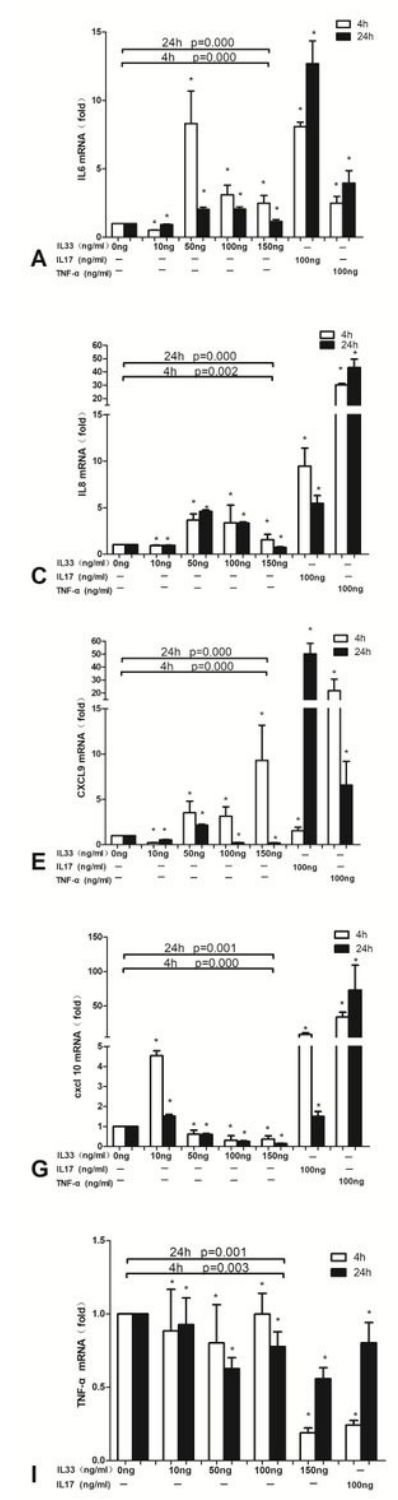
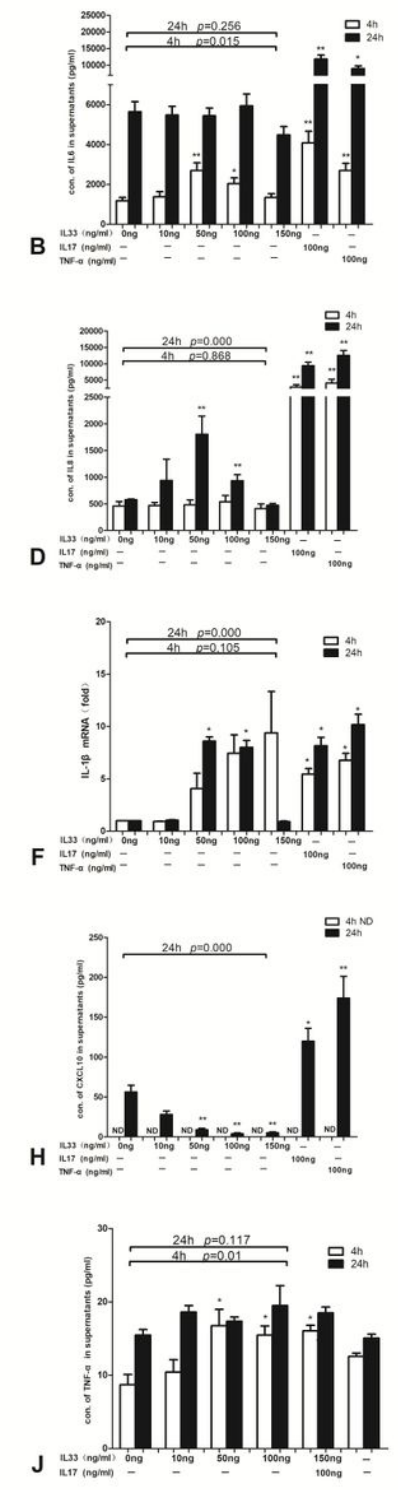

Figure 4

Effects of IL-33 on stimulated RA FLS. 『n=5区 The expression levels of cytokines and chemokines of FLS, stimulated by IL-33 in different concentrations and time points, were analyzed using RT-PCR, the amount of cytokines and chemokines released into the cell culture supernatant was determined using ELISA. (ND: not determined )A: IL-6 mRNA expression increased: $50 \mathrm{ng} / \mathrm{ml}$ of IL-33 is more powerful on RA-FLS. B: IL-6 concentration increased: $50 \mathrm{ng} / \mathrm{ml}$ of IL-33 is more powerful on RA-FLS after $4 \mathrm{~h}$, no difference after $24 \mathrm{~h}$. C: IL-8 mRNA expression increased: $50 \mathrm{ng} / \mathrm{ml}$ of IL-33 is more powerful on RA-FLS. D: IL-8 concentration increased: $50 \mathrm{ng} / \mathrm{ml}$ of IL-33 is more pow-erful on RA-FLS after 24h, no difference after $4 \mathrm{~h}$. E: CXCL9 mRNA expression in-creased: $50 \mathrm{ng} / \mathrm{ml}$ of IL-33 is more powerful on RA-FLS after $24 \mathrm{~h}$, in contrast, $150 \mathrm{ng} / \mathrm{ml}$ of IL-33 is more powerful on RA-FLS after $4 \mathrm{~h}$. F: IL-1 $\beta m R N A$ expression increased: $50 \mathrm{ng} / \mathrm{ml}$ of IL-33 is more powerful on RA-FLS after 24h, in contrast, $150 \mathrm{ng} / \mathrm{ml}$ of IL-33 is more powerful on RA-FLS after 4h. G: CXCL10 mRNA expres-sion decresed: $150 \mathrm{ng} / \mathrm{ml}$ of IL-33 is more powerful on RA-FLS. H: CXCL10 concen-tration decreased: $150 \mathrm{ng} / \mathrm{ml}$ of IL-33 is more powerful on RA-FLS after 24h. IQTNFamRNA expression decresed: IL-33 is useful, but no difference between different concentrations of IL-33. J: TNF-a concentration increased in IL-33 stimulated groups in $4 \mathrm{~h}$ not in $24 \mathrm{~h} .{ }^{*} \mathrm{P}<0.05$, ${ }^{*} \mathrm{P}<0.01$ as assessed by Kruskal-Wallis test and Mann-Whitney $\mathrm{U}$ test. 